\title{
Study of Piston Thermo-Elastic Behaviour under Thermomechanical Solicitations
}

\author{
M. Mechalikh ${ }^{1}$, A. Benhammou ${ }^{2}$, I. Zidane ${ }^{1}$ and A. Bettahar ${ }^{1}$ \\ ${ }^{1}$ Laboratory of Rheology and Mechanics (LRM), Faculty of Technology, \\ Hassiba Benbouali University of Chlef, Hay Salem, national road N ${ }^{\circ} 19-02000$, Algeria \\ ${ }^{2}$ Laboratory of Mechanics and Energy (LME), Faculty of Technology, \\ Hassiba Benbouali University of Chlef, Hay Salem, national road N $19-02000$, Algeria \\ *Email: m.mechalikh@univ-chlef.dz
}

\begin{abstract}
The piston material choice is a major factor in the design stages of internal combustion engines for its importance to improving the durability and the operation reliability during the piston life cycle. Indeed, even as many researches have been conducted for a long time to improve the piston performances in the diesel engine, considerable numbers of piston damages still significantly occur. This research work is an assessment by the finite element method (FEM) of a set of piston materials for the purpose of being used in a direct injection diesel engine. The main objective is to predict stresses concentrations and the clearance between the piston and the cylinder (to avoid metal-metal adhesion) from thermomechanical solicitations. The stresses and deformations are evaluated in a 3D piston model by using ABAQUS software. A first assessment step is performed in heat convection/conduction modes to determine the temperature distribution. Then, this last one is coupled to the pressure field resulting from the gas combustion in order to compute stresses and the magnitude displacement. The obtained results show that the austenitic steel AS12UNG with fibre-reinforced possess low thermomechanical stress values compared to other material types. This material allows a minimum failure risk and therefore contributes to the enhancement of the piston design.
\end{abstract}

Keywords: Deutz V8-FL413 engine; piston-cylinder; piston material; thermomechanical deformations / stresses; FEM.

\section{INTRODUCTION}

FEM piston thermal and mechanical analysis gives rise to an extensive number of studies [1-9]. Hence, many researchers studied this phenomenon focused on the FE analysis of strains/stresses by advanced numerical methods [10-14]. In recent years, an interesting work of Ayatollahi et al, [15] has been carried out specifically on the thermo-mechanical fatigue life assessment of a diesel engine piston in order to compute its high cycle fatigue safety factor and low cycle fatigue life using aluminium-silicon alloy material. Another study on the causes of the piston failures is performed in passenger car diesel engines by the establishment of a test program [16]. In this study, an experimental analysis of the fractured pistons revealed that thermo-mechanical fatigue initiation appears as a result of primary silicon phase cracking and subsequent micro-crack formation due to excessive thermomechanical loading. In fact, a piston is the most solicited part of the engine; it has the function of transmitting the mechanical energy to the crankshaft via the connecting rod. It is fitted with three segments that allow sealing against the combustion gases. 
This work is part of a research project with the purpose to study the entire piston diesel engine with direct injection which contributes to improving the piston performances in the industry development. The main objective is to use FEM analysis of different piston materials to forecasting the damage resulting from thermomechanical solicitations. This study will be helping to avoid many problems encountered in the piston-cylinder system by reviewing some specifics during the design stages. Among these problems, we can mention piston damages, seizures, fractures and noise [16]. The studied piston has a hollow hemisphere mounted by a hollow cylinder form "Figure 1". Firstly, the numerical model is performed only in heat convection/conduction mode to determine the temperature distribution. Secondly, in the model of the piston, the obtained temperature is coupled to the pressure field resulting from the gas combustion loads in order to compute stresses and the magnitude displacement in the piston with assumption to consider the worst-case where the piston position is at the upper limit call TDC (Top dead centre) at explosion time, in this period the combustion gases generate the max pressure value. Different piston materials analysed are aluminum alloy, steel (Cr-Mo), austenitic steel AS12 UNG, AS12 UNG fibre reinforced and cast iron.
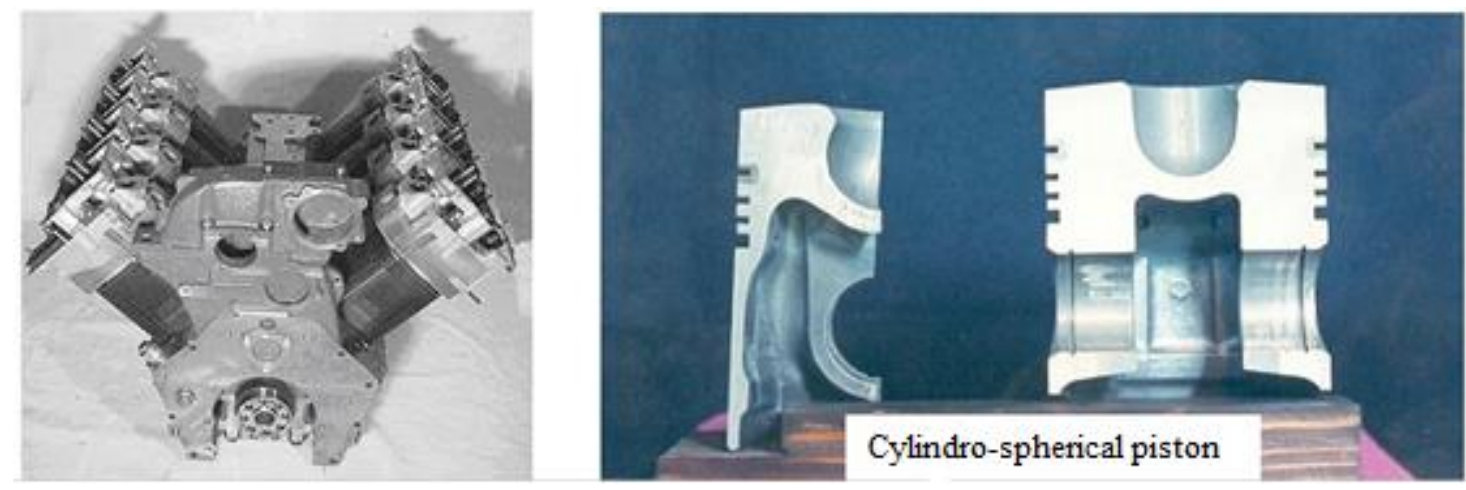

Figure 1. Diesel engine V-8 Deutz type F8L413 [10].

(Abbes MT, Maspeyrot P, Bouif A, Frene J, Proceedings of the Institution of Mechanical

Engineers, Part D: Journal of Automobile Engineering (218) pp. 395-409, copyright () 2004 by (Copyright Holder) Reprinted by Permission of SAGE Publications, Ltd.)

\section{NUMERICAL MODELLING OF THE PISTON}

\section{Model and Geometry}

The piston, mounted in the Deutz V8- F8L413 engine, is modelled by using ABAQUS/Standard FE software. In order to exam the thermomechanical behaviour of different materials, the same geometry of the piston, shown in Figure. 1, is modelled in cartesian coordinates. From accurate measurements, it is drawn directly by mean of the part module in Figure 2. The parameter conditions are summarized in Table. 1.

Table 1. Modelling parameters.

\begin{tabular}{lc}
\hline Model & Coupled temperature displacement \\
\hline Mech type & Quadratic tetrahedral C3D10MT \\
Total element number & 54258 \\
Total node number & 89393 \\
\hline
\end{tabular}



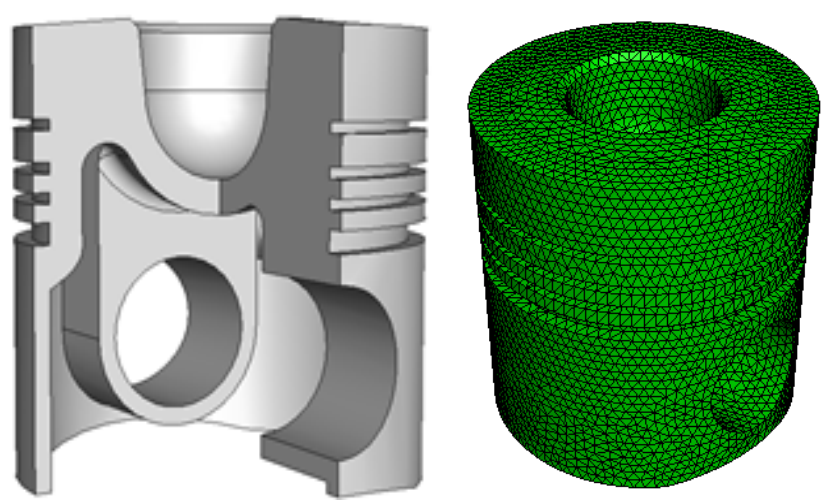

Figure 2. Piston modelling.

\section{Thermal Model}

In the thermal analysis, the main goal is to analyse the transfer of heat flux between the piston and its surroundings with different temperatures. These calculations are basically conducted through two main modes of heat transfer: thermal conduction and thermal convection. Thermal radiation is neglected in this analysis.

\section{Thermal conduction}

Thermal conduction is a heat transfer mode through the continuous piston material. The considered worst case (power strokes) where the piston is subjected to the high temperature and pressure generated from explosion gases permit to analyse the problem in a steady-state model, thereby the conduction equation is written as:

$$
-k A \vec{\nabla} T=0
$$

The proportionality constant is called the thermal conductivity coefficient ' $k$ '.

\section{Thermal convection}

Thermal convection occurs on the piston surfaces with combustible gas, lubricant fluid and cooling fluid. The heat flux equation of thermal convection stated in Eq. (2), expresses the proportionality to the temperature difference between the piston surface temperature, $T_{s}$ and the surrounding fluids temperature, $T_{f}$ and the heat flux area, $A$. The heat transfer coefficient, $h$, is dependent on fluid properties.

$$
q_{x} n_{x}+q_{y} n_{y}+q_{z} n_{z}=h A\left(T_{s-} T_{f}\right)
$$

\section{Numerical modelling}

For the finite element analysis, the tetrahedral element with 4 nodes and 4 surfaces is used to resolve the heat transfer in the piston of Figure 3. 


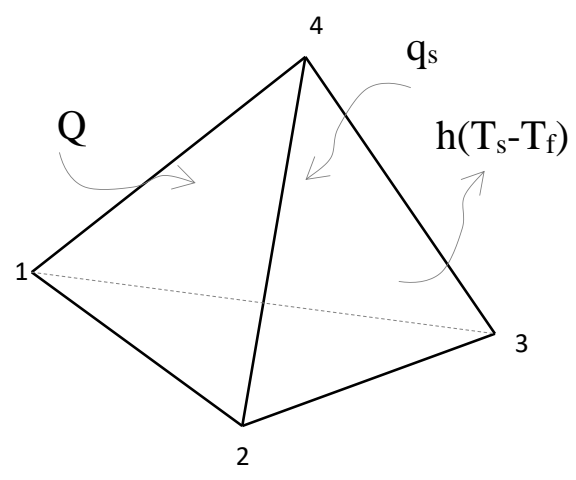

Figure 3. A tetrahedral element for thermal heat transfer calculation.

Then, Ritz variational formulation [17-19] is used in a 3D steady-state case to obtain the temperature distribution $T(x, y, z)$ which minimises the functional:

$$
I=1 / 2 \iiint_{V}\left[k_{x}(\partial T / \partial x)^{2}+k_{y}(\partial T / \partial y)^{2}+k_{z}(\partial T / \partial z)^{2}\right] d v
$$

$T(x, y, z)$ shall satisfy the following boundary conditions:

Dirichlet condition on the boundary surface $\mathrm{S}_{1}$

$$
T_{1}(x, y, z)=T_{s}
$$

Neumann condition on boundary surface $S_{2}$

$$
k_{x} \partial T / \partial x n_{x}+k_{y} \partial T / \partial y n_{y}+k_{z} \partial T / \partial z n_{z}=-q_{s}
$$

Neumann condition on boundary surface $S_{3}$

$$
k_{x} \partial T / \partial x n_{x}+k_{y} \partial T / \partial y n_{y}+k_{z} \partial T / \partial z n_{z}+h A\left(T_{s}-T_{f}\right)=0
$$

where, the initial conditions: $T(x, y, z, 0)=T_{o}(x, y, z)$. In the above boundary conditions, $q_{s}$ in Eq. (5) is the heat flux across the boundary from external sources, and $h$ is the heat transfer coefficient of the surrounding fluid at bulk fluid temperature $T_{f}$ for convective boundary condition over surface S3. $n_{x}, n_{y}$ and $n_{z}$ are respectively the directional cosines along $x, y, z$. The primary unknown quantity in finite element analysis of heat conduction in the piston is the temperature in elements and nodes. The temperature distribution $T(x, y, z)$ for each element is written as follows:

$$
T(x, y, z)=[N(x, y, z)]\{T\}
$$

Where the interpolation functions, $N(x, y, z)=\left\{N_{i} N_{j} N_{k} N_{m}\right\}$ and the nodal temperature, $\{\mathrm{T}\}=\left\{\mathrm{T}_{\mathrm{i}} \mathrm{T}_{\mathrm{j}} \mathrm{T}_{\mathrm{k}} \mathrm{T}_{\mathrm{m}}\right\}^{\mathrm{T}}$. The temperature field is computed on all nodes by solving the following system: 


$$
\{F\}=[K]\{T\}
$$

where $[K]$ expresses the global stiffness matrix, $\{F\}=\sum_{e=1}^{N E}\left\{F_{i}^{e}\right\}$ : is the global solicitation vector ('NE' element number), $\{T\}=\left\{\begin{array}{c}T_{1} \\ T_{2} \\ T_{3} \\ \cdot \\ T_{N N}\end{array}\right\}$ : expresses the overall nodal vector ('NN' node number), $i$ indicates the node index in the element $e$.

Thermal loading conditions, given by Eq. (2), are considered purely convective. They are specified under the distribution assumption of the pair $\left(h_{i}, T_{f}\right)$ on the various boundary surfaces as illustrated in Figure.4. The environment temperature $T_{f}$ is represented by $T_{g}, T_{h}$ and $T_{r}$ which respectively present the gas temperature in the combustion chamber during an engine cycle, the temperature of lubricating oil and the cooling air temperature. The values of the surrounding temperatures are $T_{g}=900^{\circ} \mathrm{C}, T_{h}=127^{\circ} \mathrm{C}$ and $T_{r}=95^{\circ} \mathrm{C}$.

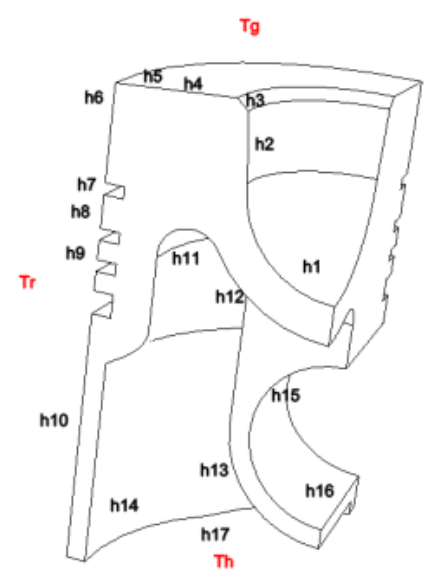

Figure 4. Thermal loading conditions.

The numerical modelling of the heat exchange between the piston and its environment is accomplished by means of experimental measurements [11]. The methodology is to take a disparity of heat flow and temperature in various points of the piston surfaces. The values of the heat transfer coefficients are given in Table 2.

Table 2. Coefficient of heat transfer $\left(\times 10^{-4} \mathrm{~W} \cdot \mathrm{mm}^{-1} \cdot \mathrm{K}^{-1}\right)$ between the piston and its environment.

\begin{tabular}{lcccccccc}
\hline $\mathrm{h}_{1}$ & $\mathrm{~h}_{2}$ & $\mathrm{~h}_{3}$ & $\mathrm{~h}_{4}$ & $\mathrm{~h}_{5}$ & $\mathrm{~h}_{6}$ & $\mathrm{~h}_{7}$ & $\mathrm{~h}_{8}$ & $\mathrm{~h}_{9}$ \\
\hline 2.1 & 2.3 & 1.4 & 1.4 & 3.0 & 0.9 & 18.2 & 3.2 & 13 \\
$\mathrm{~h}_{10}$ & $\mathrm{~h}_{11}$ & $\mathrm{~h}_{12}$ & $\mathrm{~h}_{13}$ & $\mathrm{~h}_{14}$ & $\mathrm{~h}_{15}$ & $\mathrm{~h}_{16}$ & $\mathrm{~h}_{17}$ & \\
8.0 & 7.0 & 2.0 & 3.0 & 3.2 & 25.0 & 0.5 & 0.5 & \\
\hline
\end{tabular}

\section{Mechanical Model}

The mechanical loading on the piston is generated from the combustion gases action. In the numerical modelling, the load is assumed to be uniform at worst case (piston in TDC at explosion time as in Figure 5). The applied loading is the pressure which is calculated as a 
function of the crankshaft rotation angle based on the thermodynamic cycle using real data characteristics specific to the engine F8L413 (Figure. 6).

The three degrees of freedom of the piston pin are fixed to put the piston in a static state that corresponds to the considered worst case where the piston is in the top dead centre (TDC) at the explosion time; in which the pressure is maximum $(\approx 9.58 \mathrm{MPa})$ for crankshaft angle of $370^{\circ}$.

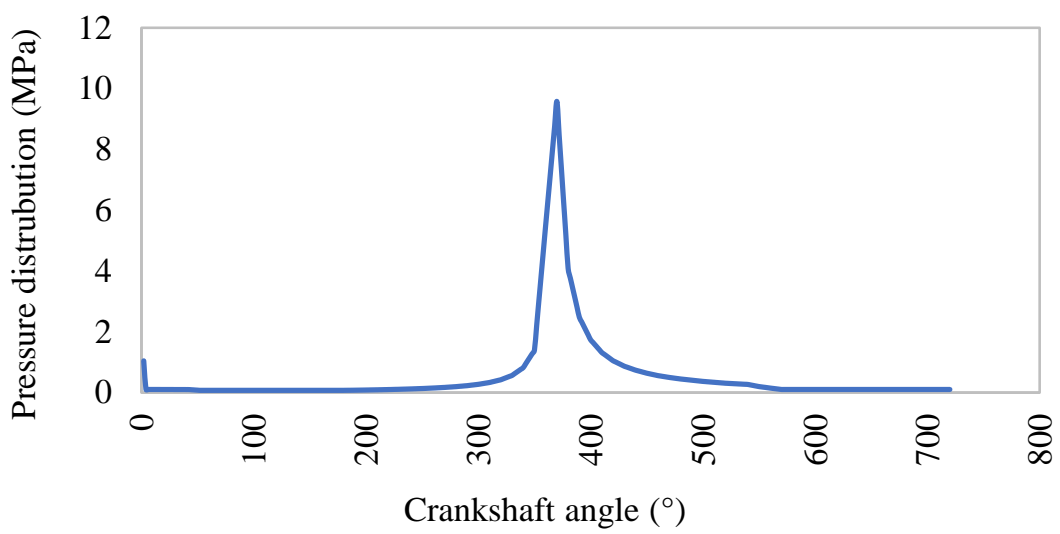

Figure 5. Pressure distribution of the combustion gases in the piston.

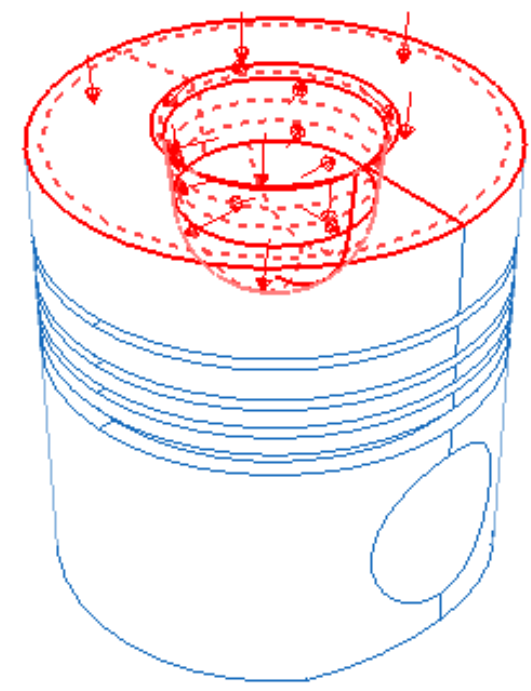

Figure 6. Mechanical loading conditions.

\section{Thermomechanical Model}

The governing equation which takes into account the mechanical, thermal loading and the expansions is written in the following form:

$$
\xi=(1+v) \Sigma / 1+v-v s 1 /{ }_{E}+\alpha\left(T-T_{0}\right) 1
$$

mechanical strain thermal strain

Where $\xi$ : Strain tensor. The stress tensor is given by:

$$
\Sigma=\lambda e 1+2 \mu \xi-k \alpha\left(T-T_{0}\right) 1
$$


With $k=3 \lambda+2 \mu=E / 1-2 v$ is the compressibility coefficient, E: Young's modulus, $v$ : is Poisson coefficient, e : trace of $\xi, \mathrm{s}:$ trace of $\Sigma, \lambda$ and $\mu$ are Lamé coefficients.

\section{Piston Materials}

The piston materials chosen to be analysed are summarized in Table 2. These materials are assumed to have an isotropic elastoplastic behaviour. The elastic part is described by using Hooke's model with Young's modulus and a Poisson's ratio.

Table 2. Piston material properties in SI units [20].

\begin{tabular}{lccccc}
\hline Type of Material & $\begin{array}{c}\text { Young's } \\
\text { modulus } \\
(\mathrm{MPa})\end{array}$ & $\begin{array}{c}\text { Poisson's } \\
\text { ratio }\end{array}$ & $\begin{array}{c}\text { Density } \\
\left(\mathrm{kg} / \mathrm{m}^{3}\right)\end{array}$ & $\begin{array}{c}\text { Thermal } \\
\text { conductivity } \\
(\mathrm{W} / \mathrm{m} . \mathrm{K})\end{array}$ & $\begin{array}{c}\text { Thermal expansion } \\
\text { coefficient } \\
\left(10^{-6} \mathrm{~K}^{-1}\right)\end{array}$ \\
\hline Austenitic steel & 190000 & 0.33 & 7800 & 20 & 12 \\
Steel-Cr-Mo & 190000 & 0.33 & 7800 & 40 & 13 \\
$\begin{array}{l}\text { Aluminum alloy } \\
\text { AS12 UNG }\end{array}$ & 55000 & 0.33 & 2700 & 150 & 24 \\
fibre-reinforced & 55000 & 0.33 & 2700 & 100 & 20 \\
Cast iron GS & 160000 & 0.33 & 7200 & 35 & 35 \\
\hline
\end{tabular}

\section{RESULTS AND DISCUSSION}

The temperature distributions of the aluminium alloy piston are plotted in Figure 7. These results are taken on the tilt plan. To validate the numerical approach, the obtained result for aluminium alloy in Figure. 7(a) is compared to that found by Li and Chin-Hsiu [11] (Figure. 7(b)) for the same material. The comparison shows a favourable relationship between the two results. For the aluminium alloy piston, we note that the temperature is the highest $\left(\approx 280^{\circ} \mathrm{C}\right)$ at the chamfers of the piston crown cavity and it decreases gradually towards the bottom of the skirt in which the temperature reaches $\left(\approx 120^{\circ} \mathrm{C}\right)$. The tendency of the temperature distribution is logic because the upper wall of the piston is subjected directly to the combustion gases.

The temperature distributions for other materials in Figure. 7(c) to 7(f) show that the maximum temperature values are similarly at the chamfers of the crown cave. This zone can be regarded as a critical area in a fatigue study. Temperatures of approximately $526{ }^{\circ} \mathrm{C}, 441$ ${ }^{\circ} \mathrm{C}, 422{ }^{\circ} \mathrm{C}$, and $307{ }^{\circ} \mathrm{C}$ are obtained respectively for AS12UNG, GS cast iron, Cr-Mo steel, and AS12UNG with fibre-reinforced. The later material and the aluminium alloy allow good temperature dissipation and therefore the most able to tolerate more temperature; this is explained by the variation in the thermal conductivity between these materials which is quantitatively affecting the temperature distribution level. The cooling fluid has a significant impact to decrease the temperature downwards to the bottom. The obtained results are in agreement with experimental temperature measurement $[9,10,12]$. 


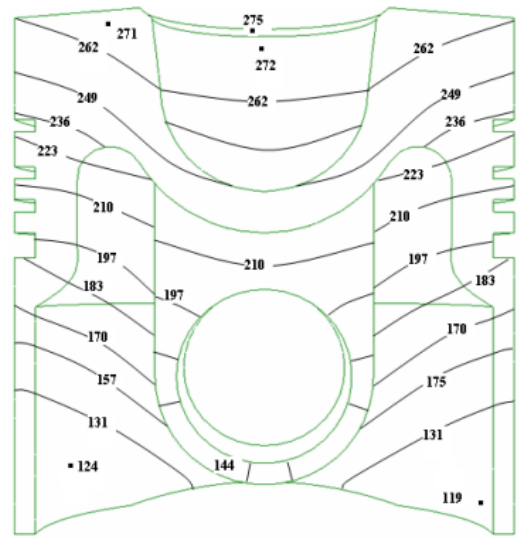

(a) aluminum alloy

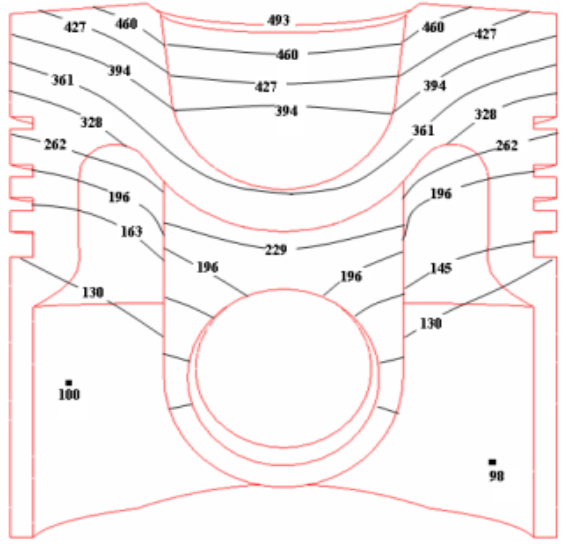

(c) austenitic steel AS12UNG

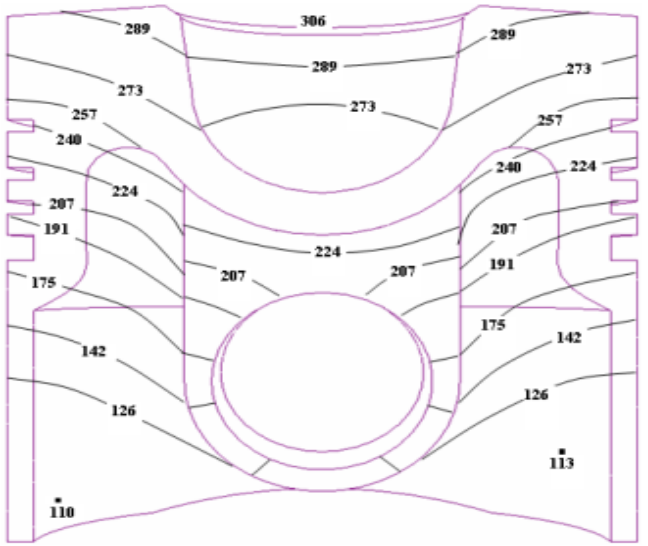

(e) austenitic steel AS12UNG with fibre reinforced

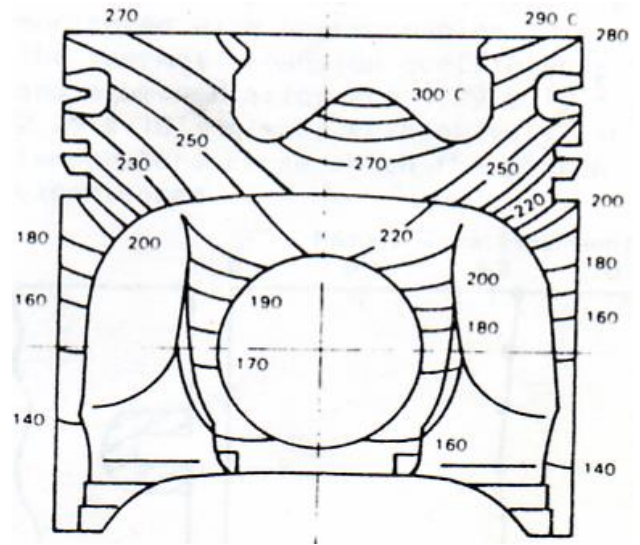

(b) Li mode for aluminum alloy

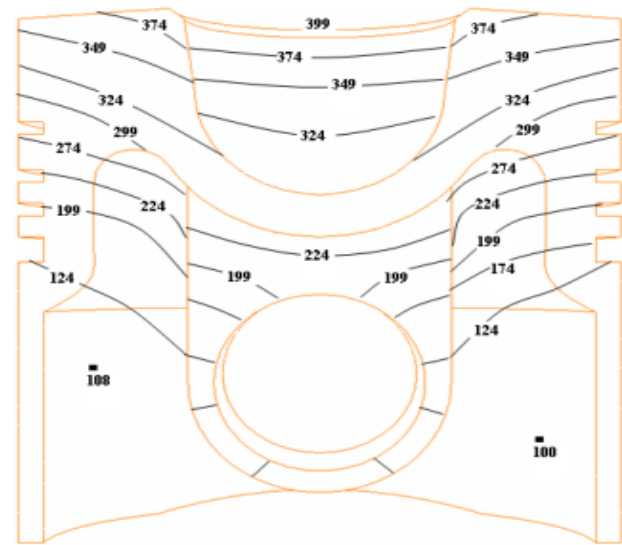

(d) steel-CrMo.

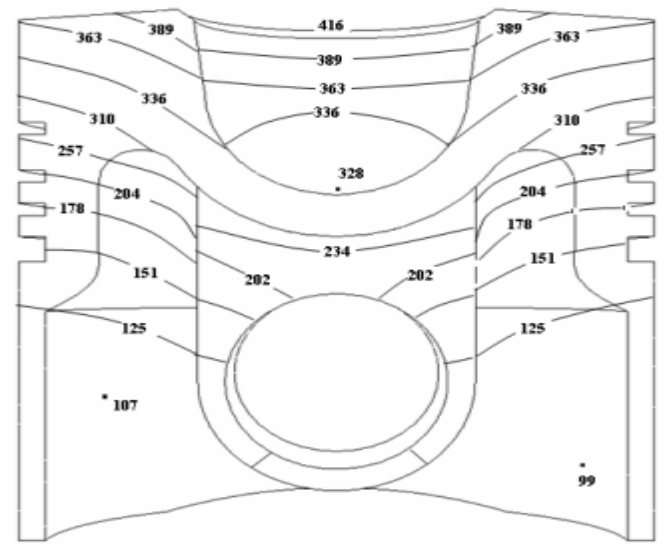

(f) cast iron.

Figure 7. Temperature field distribution in the piston for different materials.

From Figure 8, slight displacements are observed at the bottom of the skirt and they increase toward the piston crown when high displacement values are reached. The maximum one $(\approx 0.419 \mathrm{~mm})$ is corresponding to the aluminium alloy material. The minimum value of displacements at the piston crown is corresponding to the steels and cast-iron materials and it is about $0.28 \mathrm{~mm}$. a large expansion leads to insufficient clearance between the piston and the cylinder, and consequently to metal-metal adhesion. The great displacements, localised at piston-top, are explained by the thermal dilatation. The piston-top is subjected to high 
temperature compared to the mechanical loading effect. The middle of the piston is subjected to the cooling fluid which reduces the temperature effect and therefore the dilatation.

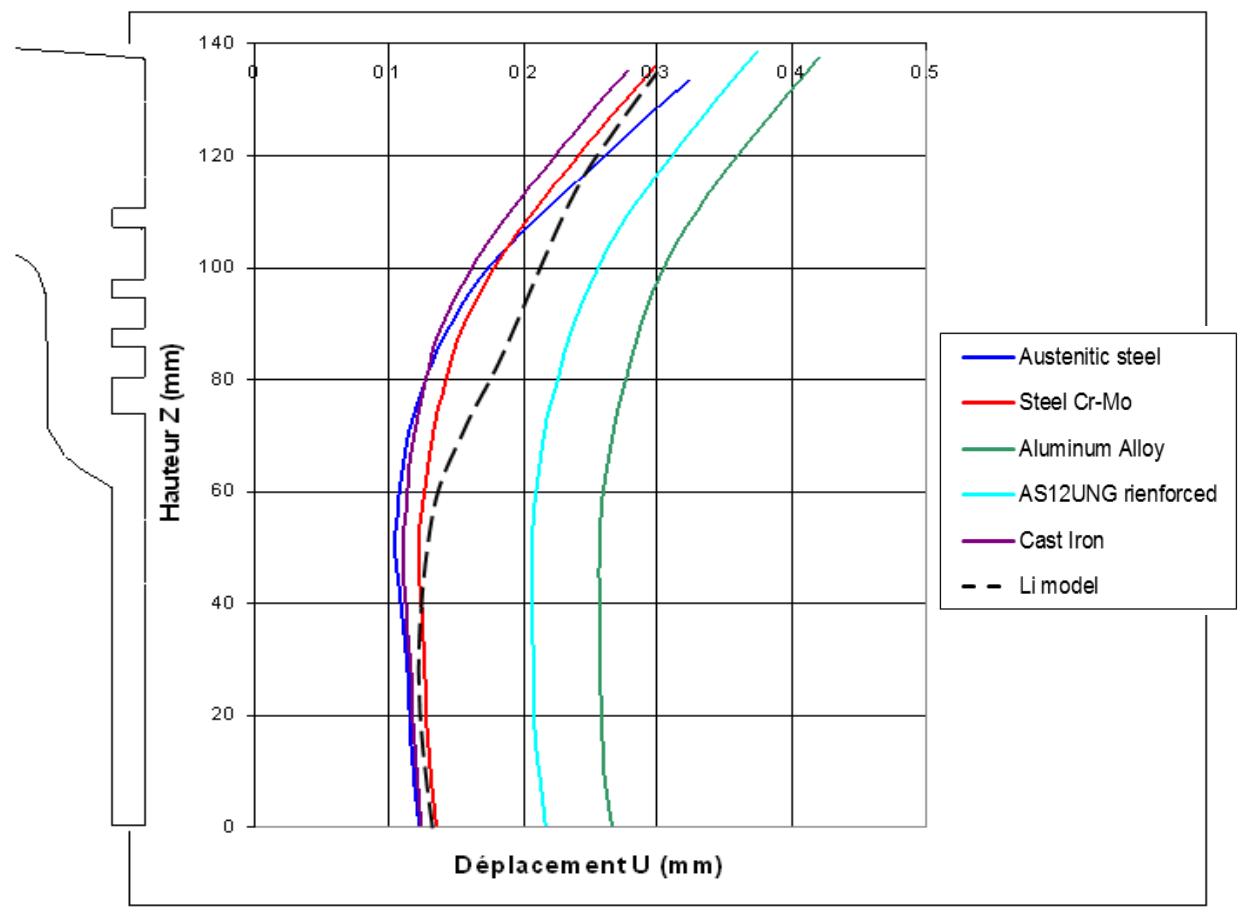

Figure 8. Displacement magnitude of the outer wall of the tilt plane.

Figure 9 and Figure 10 illustrate different views of the equivalent Von-Mises stress cartographies in the piston. It is noted that the influence of the maximum stress values is located on the piston axis at the upper edge of piston pin bosses. The influence of the stresses is minimal for the AS12UNG piston with fibre-reinforced with respect to the other materials. This difference in stress is explained by the effect of the temperature distribution. Thus, it has been found that the AS12UNG with fibre-reinforced allows a better dissipation of the temperature. Therefore, although the displacement of this material is optimal at the piston crown,

The lowest stressed piston is the one having the type of material AS12UNG with fibre-reinforced i.e. that it is the most resistant in front of the aggressive thermomechanical conditions; The mechanical characteristics of the AS12UNG with fibre-reinforced give it a good temperature dissipation and less elastic dilatation which is reflected on the thermomechanical stress impact.

\section{CONCLUSION}

In this paper, the piston is modelled by using the FE software ABAQUS/Standard. In the Modelling of the piston, the temperature is coupled to the pressure field resulting from the gas combustion loads in order to compute stresses and the magnitude displacement in the piston. Different piston materials are analysed which are: aluminium alloy, steel (Cr-Mo), AS12 UNG, AS12 UNG fibre reinforced and cast iron.

To validate the numerical approach, the obtained result of the temperature distributions for aluminium alloy is compared to that found by $\mathrm{Li}$ and al. for the same material. The comparison shows a favourable relationship between the two results. The 
tendency of the temperature distribution is logic because the upper wall of the piston is subjected directly to the combustion gases, and the bottom is lubricated. The AS12 UNG fibre reinforced material and the aluminium alloy allows a good temperature dissipation and therefore the most able to tolerate more temperature. The stress cartographies show that the concentration is located on the piston axis regardless of the material type. The thermomechanical stress has only an impact on the level of stress such as come out from the comparison. Therefore, AS12UNG with fibre reinforced possess low thermomechanical stress values compared to other material types. Slight displacements are observed at the bottom of the skirt and they increase toward the piston crown when high displacement values are reached. The maximum one $(\approx 0.419 \mathrm{~mm})$ is corresponding to the aluminium alloy material. The minimum value of displacements at the piston crown is corresponding to the steels and cast-iron materials and it is about $0.28 \mathrm{~mm}$. A large expansion of the piston crown leads to insufficient clearance between the piston and the cylinder and consequently to metalmetal adhesion.

In this study, the austenitic steel (AS12UNG) with fibre-reinforced shown good behaviour against the combined thermomechanical solicitations. This is due to its enhanced properties as the amenability to allow a good dissipation of the temperature.
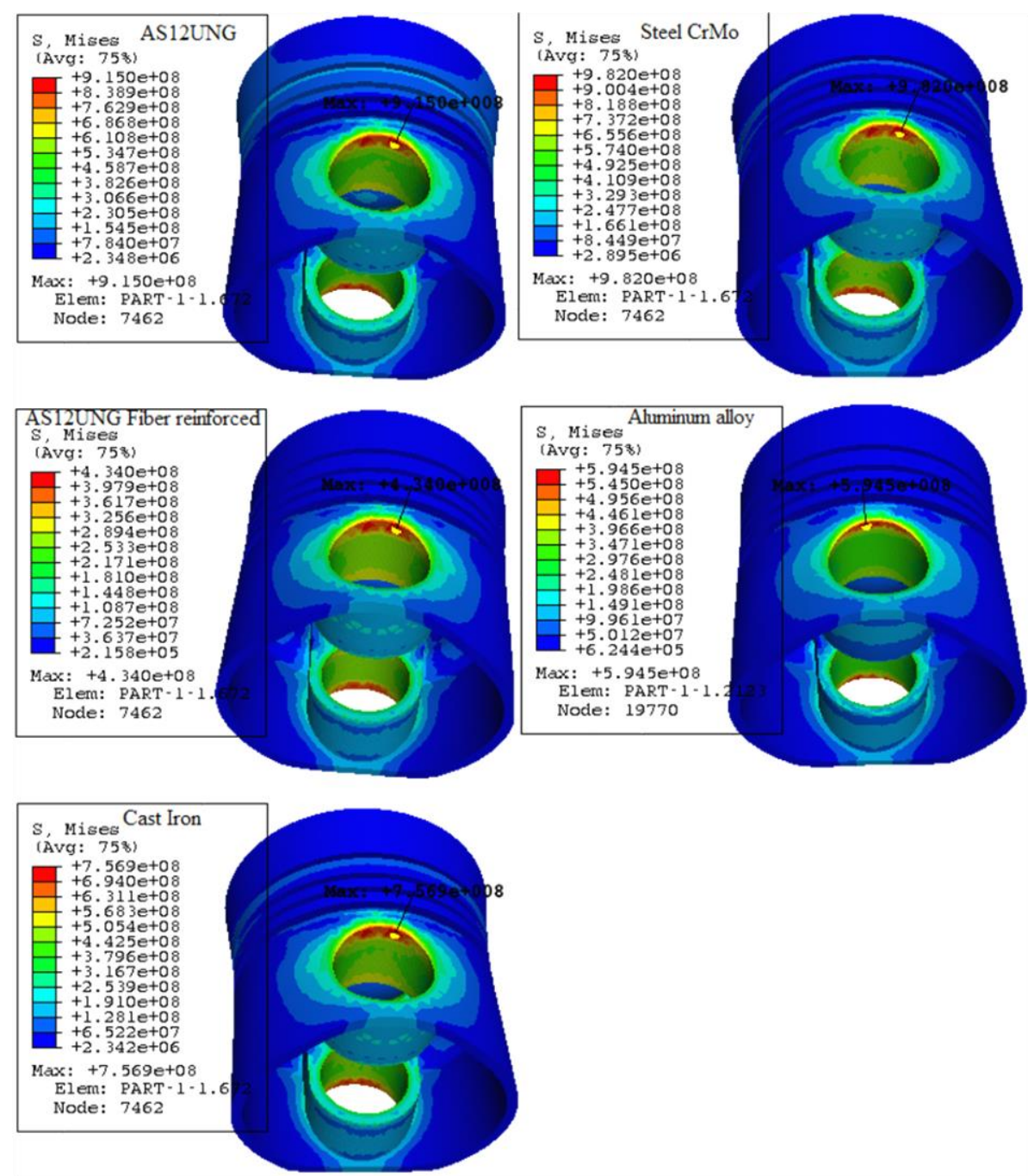

Figure 9. Different views of thermomechanical stress cartographies in the piston. 

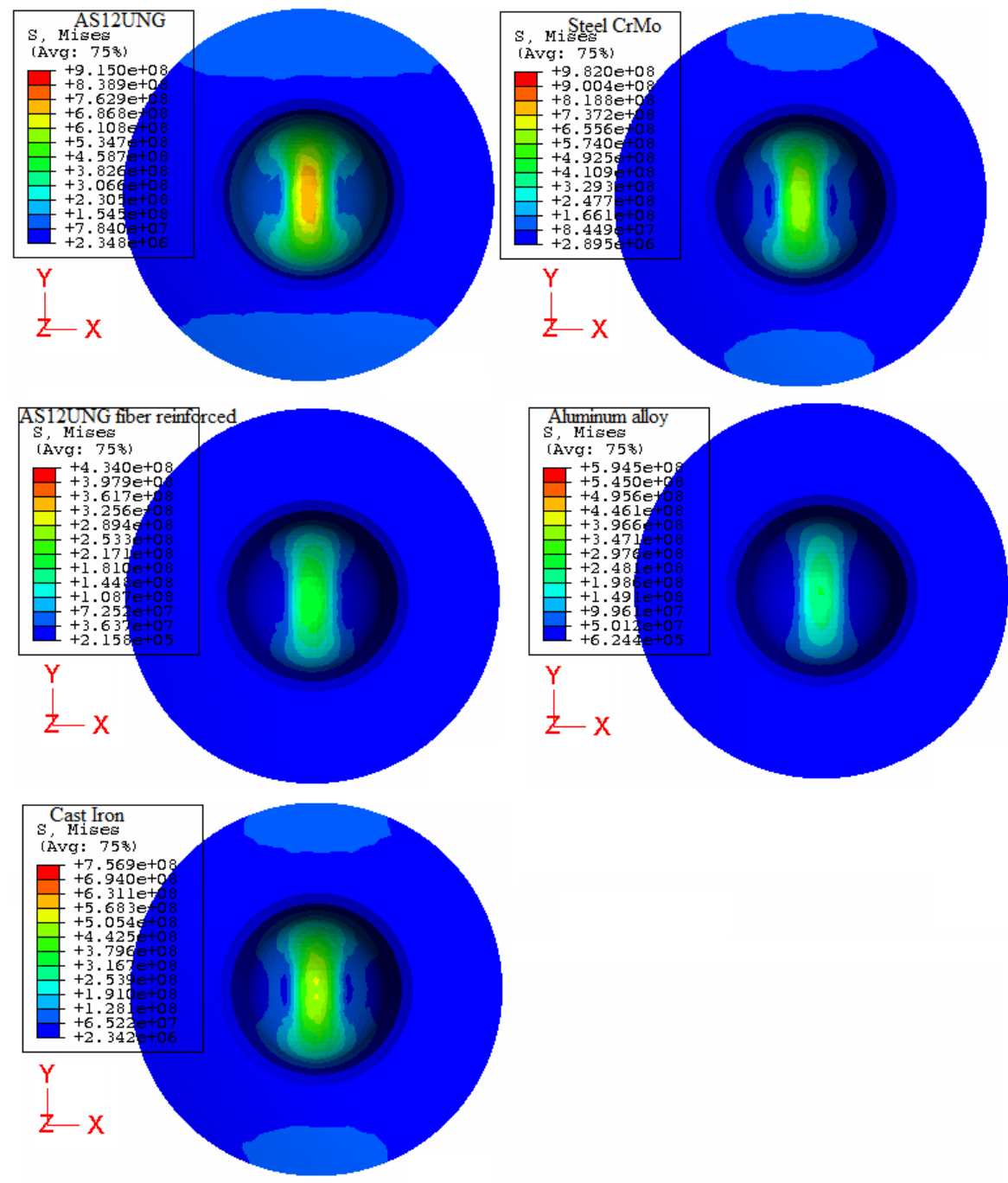

Figure 10. Different views of the thermomechanical stress cartographies in the piston.

\section{REFERENCES}

[1] Wang M, Pang JC, Zhang MX, Liu HQ, Li SX, Zhang ZF. Thermo-mechanical fatigue behaviour and life prediction of the Al-Si piston alloy. Materials Science and Engineering: A. 2018;715:62-72.

[2] Furuhama S, Suzuki H. Temperature distribution of piston rings and piston in high speed diesel engine. Bulletin of JSME. 1979;22:1788-95.

[3] Sroka ZJ, Dziedzioch D. Mechanical load of piston applied in downsized engine. Archives of Civil and Mechanical Engineering. 2015;15:663-7.

[4] Totaro PP, Westerfield Z, Tian T. Introducing a new piston skirt profile to reduce engine friction. SAE International; 2016.

[5] Liu X, Cheng D, Zhou J, Zheng Q, Mi X. Fluid-structure interaction heat transfer of piston with consideration of oil oscillating cooling and in-cylinder local heat transfer. 2017;- 61.

[6] Benhamou A, Tahar-abbes M, Maspeyrot P. Finite elements analysis of the impact of the combustion chamber type on the mechanical behaviour of the piston; Analyse par elements finis de;influence de types de chambre de combustion sur le comportement mecanique du piston. France 2005. 
[7] Liu XF, Wang Y, Liu WH. Finite element analysis of thermo-mechanical conditions inside the piston of a diesel engine. Applied Thermal Engineering. 2017;119:312-8.

[8] Andoko, Puspitasari P. Finite element analysis of surface tension on piston due to pressure variation. AIP Conference Proceedings. 2016;1778:030064.

[9] Pan J, Nigro R, Matsuo E. 3-D Modelling of heat transfer in diesel engine piston cooling galleries. SAE International; 2005.

[10] Abbes MT, Maspeyrot P, Bouif A, Frene J. A thermomechanical model of a direct injection diesel engine piston. Proceedings of the Institution of Mechanical Engineers, Part D: Journal of Automobile Engineering. 2004; 218:395-409.

[11] Li C-H. Thermoelastic behaviour of an aluminum diesel engine piston. SAE International; 1986.

[12] Szmytka F, Salem M, Rézaï-Aria F, Oudin A. Thermal fatigue analysis of automotive Diesel piston: Experimental procedure and numerical protocol. International Journal of Fatigue. 2015;73:48-57.

[13] Kenningley S, Morgenstern R. Thermal and mechanical loading in the combustion bowl region of light vehicle diesel alsicunimg pistons; reviewed with emphasis on advanced finite element analysis and instrumented engine testing techniques. SAE International; 2012.

[14] Papaioannou N, Leach F, Davy M. Thermal analysis of steel and aluminium pistons for an hsdi diesel engine. SAE International; 2019.

[15] Ayatollahi MR, Mohammadi F, Chamani HR. Thermo-Mechanical fatigue life assessment of a diesel engine piston. International Journal of Automotive Engineering. 2011;1:256-66.

[16] Floweday G, Petrov S, Tait RB, Press J. Thermo-mechanical fatigue damage and failure of modern high performance diesel pistons. Engineering Failure Analysis. 2011;18:1664-74.

[17] Hsu TR. The finite element method in thermomechanics: Routledge; 1986.

[18] Segerlind LJ. Applied finite element analysis. Larry J. Segerlind. New York: Wiley; 1976.

[19] Rao SS. Formulation and solution procedure. In: Rao SS, editor. The finite element method in engineering (Fourth Edition). Burlington: Butterworth-Heinemann; 2005. p. 467-81.

[20] Christian C. Technologie des moteurs alternatifs à combustion interne. Techniques de l'ingénieur Technologie des moteurs thermiques. 1996; base documentaire : TIB165DUO - b2800:1-32. 